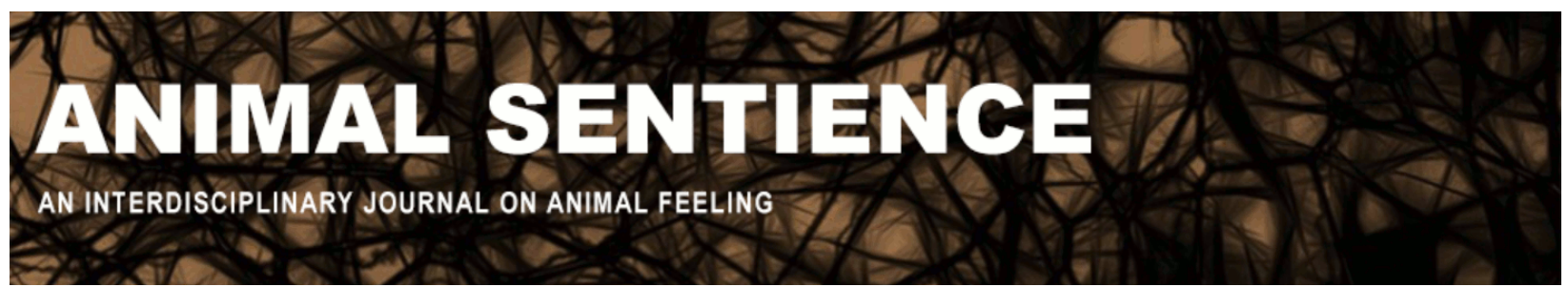

Urfer, Silvan R. (2017) Emotion in dogs: Translational and transformative aspects. Animal Sentience 14(4)

DOI: $10.51291 / 2377-7478.1228$

Date of submission: 2017-10-17

Date of acceptance: 2017-10-19

(c)

This article has appeared in the journal Animal

Sentience, a peer-reviewed journal on animal

cognition and feeling. It has been made open access,

free for all, by WellBeing International and deposited

in the WBI Studies Repository. For more information,

please contact

wbisr-info@wellbeingintl.org.

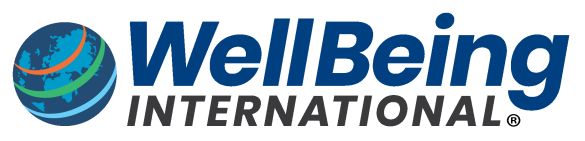

SOLUTIONS FOR PEOPLE, ANIMALS AND ENVIRONMENT 


\title{
Emotion in dogs: Translational and transformative aspects
}

Commentary on Kujala on Canine Emotions

\author{
Silvan R. Urfer \\ Dog Aging Project \\ University of Washington Medicine Pathology
}

\begin{abstract}
Kujala (2017) provides an excellent overview of most aspects of emotion in dogs; however, she does not cover a few fields of research that I think are also relevant to the topic. In this commentary, I discuss the current state of our knowledge regarding cognitive decline and behavioral disorders in dogs as potential models for human neurodegenerative disease and mental illness; how emotion and cognition in dogs interact with sex, gonadectomy, and sexual behavior; as well as the transformative potential of functional MRI imaging of the conscious dog brain in the study of comparative neurophysiology.
\end{abstract}

Silvan Urfer is a veterinarian with an interest in geroscience and comparative medicine. He is a Senior Fellow at University of Washington Medicine Pathology and serves as the veterinary informatics officer for the Dog Aging Project. His research interests include using privately owned pet dogs as models for various age-related and other diseases in humans, including those that affect the brain.

www.dogagingproject.com

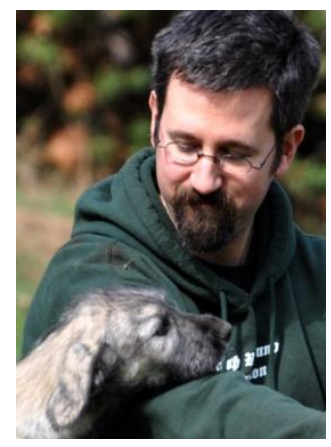

\section{Introduction}

I agree with Kujala (2017) that while subjective aspects of emotions are essentially unmeasurable and thus unprovable, the various anatomical and functional parallels between human and canine brains discussed in her target article make it very likely that emotional states (including the capacity for suffering) exist in dogs. It follows that in the absence of evidence to the contrary, and for both ethical and animal welfare reasons, we should generally base our treatment of dogs and other animals on a variant of Pascal's Wager: It is better to assume the existence of emotions where none exist than it is to assume their absence where they do exist. [See also Birch 2017, this journal - ed.]

While Kujala's review does an admirable job of summarizing most currently known aspects of canine emotions, it also leaves a few gaps that I would like to address:

\section{Canine Neurodegenerative and Behavioral Disorders as Models for Human Disease}

As our understanding of canine behavioral disorders has grown, so has our knowledge of how the canine and human brains can be affected by similar structural and/or functional pathologies whose study has considerable translational potential. 
In particular, the aging dog brain has numerous physiological and anatomical similarities to the aging human brain (Head, Rofina et al. 2008; Head 2011; Chapagain, Viranyi et al. 2017). This presents several potentially interesting models for comparative study. Foremost among these is Canine Cognitive Decline (CCD), which has been suggested as a model for human Alzheimer's Disease (AD) (Oates 2014; Schütt, Helboe et al. 2016): Much like AD, CCD is associated with increased anxiety and loss of natural sleep patterns in addition to the progressive decline of cognitive function (Schütt, Toft et al. 2015), and much like brain samples from humans with $A D$, brain samples from dogs with $C C D$ exhibit neurodegeneration accompanied by the development of amyloid plaques and tau tangles (Schmidt, Boltze et al. 2015; Smolek, Madari et al. 2016). The aged privately owned dog thus represents a potentially translational model of $A D$ in an environment that resembles the human environment to a much greater degree than could ever be achieved in a laboratory setting (Gilmore and Greer 2015; Kaeberlein, Creevy et al. 2016).

Another potential translational model is found in stereotypical and obsessively repetitive behaviors such as tail chasing and compulsive flank sucking, which are more commonly observed in certain breeds and have been shown to share a similar neurobiology with human Obsessive-Compulsive Disorder (OCD) (Tiira, Hakosalo et al. 2012; Ogata, Gillis et al. 2013). Other examples of canine brain diseases that have human analogs include but are not limited to the neuronal ceroid lipofuscinoses, which represent a cluster of fatal inherited degenerative brain diseases that have been described in at least 20 different dog breeds (Katz, Rustad et al. 2017) and are also present in humans (Nita, Mole et al. 2016).

\section{Sex, Gonadectomy, and Sexual Behavior}

There is a considerable body of evidence regarding the influence of sex and gonadectomy on cognition and (by implication) emotion in dogs. For example, we know that female and gonadectomized dogs are more likely to develop CCD than male or intact dogs (Azkona, GarciaBelenguer et al. 2009). CCD also progresses more rapidly in neutered male dogs compared to intact males (Hart 2001). It has been shown that female, but not male, dogs respond to a size constancy violation in a behavioral test of object permanence (Müller, Mayer et al. 2011); that male and female dogs show significant differences in social learning (Fugazza, Mongillo et al. 2017); and that intact female dogs learn a maze task in fewer attempts than intact male dogs, but that spayed female dogs perform worse than intact females (Mongillo, Scandurra et al. 2017). It would thus appear that sex and gonadectomy have important implications for canine cognitive function that merit further scientific attention. It is not unreasonable to assume that those differences also extend to and interact with emotional states.

It is also likely that emotional states influence and are influenced by sexual behavior. While recent research appears to have somewhat neglected the emotional aspects of sexual behavior in non-human animals, a substantial number of studies from past decades exists on the topic. For example, it has been shown that female dogs exhibit sexual preference or rejection towards individual male dogs (Beach and LeBoeuf 1967), that sexually experienced neutered male dogs show increased mounting behavior compared to inexperienced neutered males 
(Beach 1970), and that characteristic physiological responses during coitus that are correlated with male or female orgasm in humans are also present in dogs (Fox and Fox 1971).

\section{Transformative Potential of Imaging the Conscious Dog Brain}

While Kujala touches on the recently implemented methods for imaging conscious brain activity using MRI, I think the advances that have been made in this field in particular are worth pointing out in more detail. The methods now published allow us to train dogs to undergo MRI imaging while fully awake, and thus open up exciting possibilities for observing the conscious canine brain in real time (Berns, Brooks et al. 2012). This in turn allows us to draw parallels between canine and human brain function that are not merely based on comparative anatomy and physiology, but actual live brain imaging of the conscious dog. This represents a paradigm shift in cognitive research that is relevant not only to the presence of emotion, but to all aspects of canine cognitive function. The method has thus far been used to study reactions to olfaction (Jia, Pustovyy et al. 2014; Jia, Pustovyy et al. 2016), processing of spoken language (Andics, Gábor et al. 2016), and face recognition (Cuaya, Hernández-Pérez et al. 2016); it will no doubt be expanded to other fields of study in the future (Huber and Lamm 2017).

In conclusion, it is also worth noting that results from this new method have been used to argue in favor of important ethical and animal welfare implications because they do provide evidence of a capacity for emotion and, by implication, suffering that needs to be taken into account when judging the ethical aspects of using dogs in invasive experiments (Bailey and Pereira 2017).

\section{References}

Andics, A., Gábor, A., Gácsi, M., Faragó, T., Szabó, D., Miklósi, Á., 2016. Neural mechanisms for lexical processing in dogs. Science 253, 1030-1032.

Azkona, G., Garcia-Belenguer, S., Chacón, G., Rosado, M., León, M., Palacio, J., 2009. Prevalence and risk factors of behavioural changes associated with age-related cognitive impairment in geriatric dogs. J Sm Anim Pract 50, 87-91.

Bailey, J., Pereira, S., 2017. Advances in neuroscience imply that harmful experiments in dogs are unethical. J Med Ethics Jul 24.

Beach, F., 1970. Coital behavior in dogs: VI. Long-term effects of castration upon mating in the male. J Comp Phys Psych 70, 1-32.

Beach, F., LeBoeuf, B., 1967. Coital behaviour in dogs. I. preferential mating in the bitch. Anim Behav 15, 546-558.

Berns, G., Brooks, A., Spivak, M., 2012. Functional MRI in awake unrestrained dogs. PLoS One 5, e38027.

Birch, J., 2017. Animal sentience and the precautionary principle. Animal Sentience 16(1).

Chapagain, D., Viranyi, Z., Wallis, L., Huber, L., Serra, J., Range, F., 2017. Aging of Attentiveness in Border Collies and Other Pet Dog Breeds: The Protective Benefits of Lifelong Training. Front Aging Neurosci 9, 100. 
Cuaya, L., Hernández-Pérez, R., Concha, L., 2016. Our Faces in the Dog's Brain: Functional Imaging Reveals Temporal Cortex Activation during Perception of Human Faces. PLoS One 11, e0149431.

Fox, C., Fox, B., 1971. A comparative study of coital physiology, with special reference to the sexual climax. J Reprod Fert 42, 319-336.

Fugazza, C., Mongillo, P., Marinelli, L., 2017. Sex differences in dogs' social learning of spatial information. Animal Cognition 20, 789-794.

Gilmore, K., Greer, K., 2015. Why is the dog an ideal model for aging research? Exp Gerontol 71, 14-20.

Hart, B., 2001. Effect of gonadectomy on subsequent development of age-related cognitive impairment in dogs. J Am Vet Med Assoc 219, 51-56.

Head, E., 2011. Neurobiology of the aging dog. Age (Dordr) 33, 485-496.

Head, E., Rofina, J., Zicker, S., 2008. Oxidative stress, aging, and central nervous system disease in the canine model of human brain aging. Vet Clin North Am Small Anim Pract 38, 167.178.

Huber, L., Lamm, C., 2017. Understanding dog cognition by functional magnetic resonance imaging. Learn Behav 45, 101-102.

Jia, H., Pustovyy, O., Waggoner, P., Beyers, R., Schumacher, J., Wildey, C., Barrett, J., Morrison, E., Salibi, N., Denney, T., Vodyanoy, V., Deshpande, G., 2014. Functional MRI of the olfactory system in conscious dogs. PLoS One 9, e86362.

Jia, H., Pustovyy, O., Wang, Y., Waggoner, P., Beyers, R., Schumacher, J., Wildey, C., Morrison, E., Salibi, N., Denney, T., Vodyanoy, V., Deshpande, G., 2016. Enhancement of Odor-Induced Activity in the Canine Brain by Zinc Nanoparticles: A Functional MRI Study in Fully Unrestrained Conscious Dogs. Chem Senses 41, 53-67.

Kaeberlein, M., Creevy, K., Promislow, D., 2016. The dog aging project: translational geroscience in companion animals. Mammalian Genome 27.

Katz, M., Rustad, E., Robinson, G., Whiting, R., Student, J., Coates, J., Narfstrom, K., 2017. Canine neuronal ceroid lipofuscinoses: Promising models for preclinical testing of therapeutic interventions. Neurobiol Dis 108, 277-287.

Kujala, M., 2017. Canine emotions as seen through human social cognition. Animal Sentience 2017.013.

Mongillo, P., Scandurra, A., D'Aniello, B., Marinelli, L., 2017. Effect of sex and gonadectomy on dogs' spatial performance. Appl Anim Behav Sci 191, 84-89.

Müller, C., Mayer, C., Dörrenberg, S., Huber, L., Range, F., 2011. Female but not male dogs respond to a size constancy violation. Biol Lett 7, 689-691.

Nita, D., Mole, S., Minassian, B., 2016. Neuronal ceroid lipofuscinoses. Epileptic Disord 18, 7388.

Oates, S., 2014. Uncloaking cognitive decline: the emergence of canine cognitive dysfunction in veterinary medicine and its implications for understanding Alzheimer's disease. Vet Herit 37, 47-51.

Ogata, N., Gillis, T., Liu, X., Cunningham, S., Lowen, S., Adams, B., Sutherland-Smith, J., Mintzopoulos, D., Janes, A., Dodman, N., Kaufman, M., 2013. Brain structural abnormalities in Doberman pinschers with canine compulsive disorder. Prog Neuropsychopharmacol Biol Psychiatry 45, 1-6. 
Schmidt, F., Boltze, J., Jäger, C., Hofmann, S., Willems, N., Seeger, J., Härtig, W., Stolzing, A., 2015. Detection and Quantification of $\beta$-Amyloid, Pyroglutamyl $A \beta$, and Tau in Aged Canines. J Neuropathol Exp Neurol 74, 912-923.

Schütt, T., Helboe, L., Pedersen, L., Waldemar, G., Berendt, M., Pedersen, J., 2016. Dogs with Cognitive Dysfunction as a Spontaneous Model for Early Alzheimer's Disease: A Translational Study of Neuropathological and Inflammatory Markers. J Alzheimers Dis 52, 433-449.

Schütt, T., Toft, N., Berendt, M., 2015. Cognitive Function, Progression of Age-related Behavioral Changes, Biomarkers, and Survival in Dogs More Than 8 Years Old. J Vet Intern Med 29, 1569-1577.

Smolek, T., Madari, A., Farbakova, J., Kandrac, O., Jadhav, S., Cente, M., Brezovakova, V., Novak, M., Zilka, N., 2016. Tau hyperphosphorylation in synaptosomes and neuroinflammation are associated with canine cognitive impairment. J Comp Neurol 524, 874-895.

Tiira, K., Hakosalo, O., Kareinen, L., Thomas, A., Hielm-Björkman, A., Escriou, C., Arnold, P., Lohi, H., 2012. Environmental effects on compulsive tail chasing in dogs. PLoS One 7, e41684. 